\title{
A New $\beta$-shaped Microstrip Patch for Bluetooth
}

\author{
Sakshi and Manisha Bharti \\ Department of Electronics and Communication Engineering, National institute of technology, Delhi, 110040, India. \\ Corresponding Author: sakshi@nitdelhi.ac.in
}

\begin{abstract}
This paper introduced the design of a low-profile patch antenna. The demonstrated antenna can be used for Bluetooth application. At $2.4 \mathrm{GHz}$ the antenna has good properties. The antenna is built on flame resistant (FR4) substrate with a total size of $110 \mathrm{mmx} 110 \mathrm{~mm}$. To comprehend the resonant performance of the antenna a parametric analysis is performed by changing the radiating length and circular slot radius of $\beta$ shaped antenna.
\end{abstract}

Keywords: Microstrip patch antennas; Bluetooth application; return loss; Radiation pattern; parametric analysis.

\section{INTRODUCTION}

Bluetooth technology is a short-range wireless networking system that uses low-energy waves to allow Bluetooth devices to transmit wireless data. This is similar to $\mathrm{Wi}-\mathrm{Fi}$ as it works on radio waves. Bluetooth is a wireless communication protocol used to transfer data over a short distance between fixed and mobile devices using $2.4 \mathrm{GHz}$ to $2.485 \mathrm{GHz}$ short wavelength UHF radio waves in industrial, science and medical radio bands, and to establish personal networks (PANs).The rapid growth in connectivity has resulted in tremendous demand for small size antennas, low profile, low production costs and simple integration with feeding network[1]-[3].Microstrip patch antennas were extensively carried out because of the advantages of compact size, light weight and simple manufacturing [4]-[10].Microstrip line is a non-symmetrical strip line which is nothing more than a parallel plate transmission line with a dielectric substrate, one side of which is metalized ground and another (top) face has a conducting strip of some width 'w and thickness 't.' The microstrip line has some advantages over strip lines, coaxial line and wave guide.1) Full conductor pattern can be deposited and handled on a single dielectric substrate supported by a single ground plane made of metal. Thus fabrication costs would be substantially lower than strip line, co-axial or waveguide circuit. (2) As microstrip line could be a planner structure, each packaged and unpackaged semiconductor chip are often handily hooked up to microstrip component. (3) Also, Simple access to the top surface makes it possible to install passive and active discrete devices as well as to make minor changes after the circuit has been manufactured. It also enables for probing.

However, microstrip has some limitations also. Microstrip works as an open circuit and due to nearby conductors have higher radiation losses or interferences. These losses can be minimized by choosing lean substrates with high dielectric constants. A discontinuity in the electric field and magnetic field is caused due to the proximity of the air-dielectric interface, with the microstrip conductor at the interface. This results in a microstrip configuration that transforms into a mixed dielectric transmission system with impure TEM mode propagation.

A ' $\beta$ ' shaped microstrip patch antenna design is suggested in this article. This antenna resonates at $2.4 \mathrm{GHz}$ for the Bluetooth function. The geometry of the demonstrated antenna is shown in the section 2 and parametric study of the proposed antenna is presented by changing the length of patch (p_x). All simulation results are present in section 3 . 


\section{PROPOSED ANTENNA DESIGN}

The geometry of the proposed antenna $\beta$ shaped microstrip patch antenna is shown in fig 1 (a) and fig (b). All the measurements are in $\mathrm{mm}$. The proposed ' $\beta$ ' shaped antenna is in three-layer structure patch, substrate and ground. Here the substrate chosen for the development of the proposed antenna is $3.2 \mathrm{~mm}$ thick flame-resistant epoxy and the field dimension is $110 \mathrm{~mm}$ x $110 \mathrm{~mm}$.

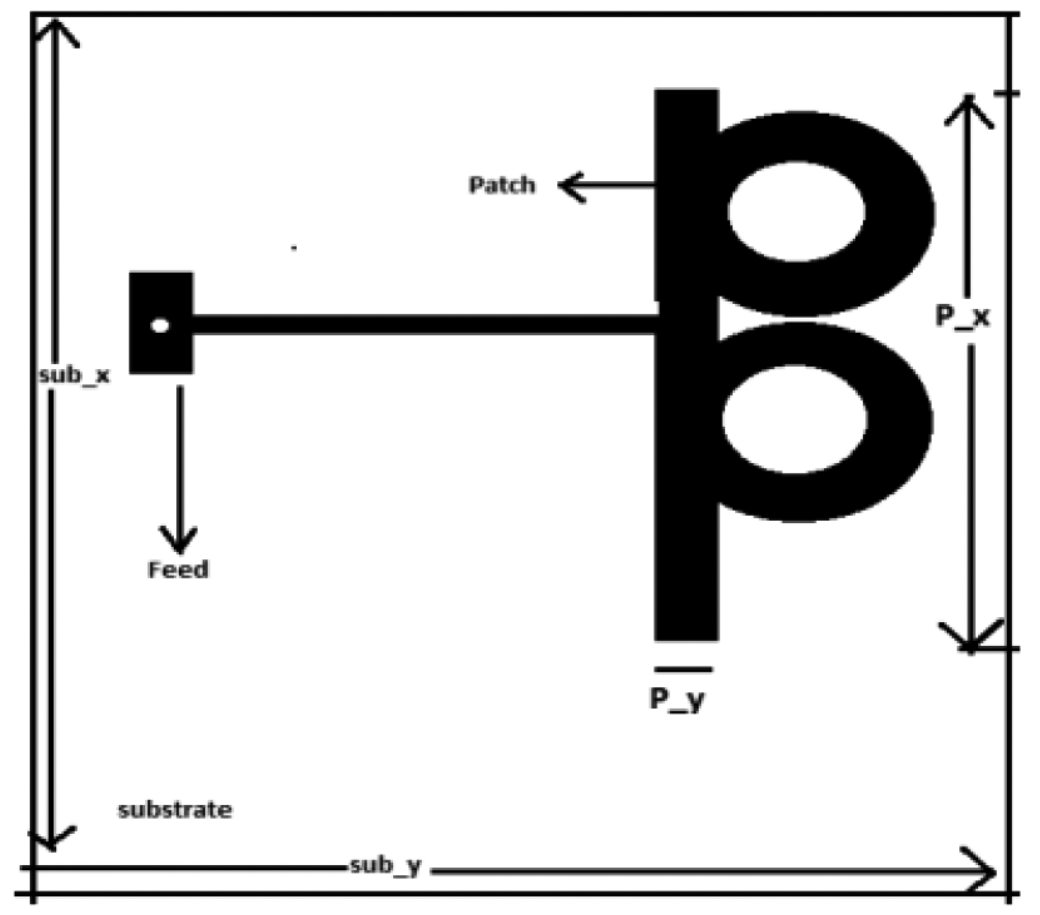

(a)

\section{Patch}

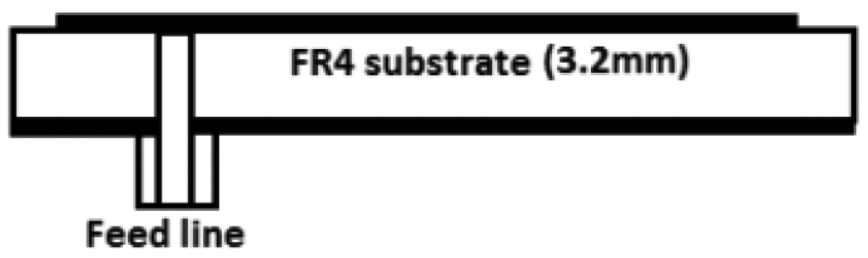

(b)

Figure 1. (a) proposed patch antenna design top (b) side 
The feeding technology in microstrip patch antenna are characterized in two classes, which are contacting (direct) and non-contacting (indirect). Most popular technique that are used such as coaxial probe feeding, aperture coupled, proximity coupling and microstrip feeding. In this paper coaxial feeding is used. Here the entire structure is taken care of by a co-axial feeding at the position $(\mathrm{X} 0, \mathrm{Y} 0)=(34 \mathrm{~mm}, 25 \mathrm{~mm})$. When position of feed changes then, there is a little change in the resonance frequency, but return loss change noticeably. The patch's form is designed such that it can resonate at $2.4 \mathrm{GHz}$, which is the Bluetooth application's operating frequency. The patch has two circular slots with radius $\mathrm{R}$ in and $\mathrm{R}$ out as seen in Table 1 . To make antenna resonate at $2.4 \mathrm{GHz}$ the circular slot is taken as $9 \mathrm{~mm}$.

Table 1. Proposed antenna parameter

\begin{tabular}{|l|l|l|}
\hline Name & Value & Unit \\
\hline Sub_x & 110 & $\mathrm{~mm}$ \\
\hline Sub_y & 110 & $\mathrm{~mm}$ \\
\hline Sub_z & 3.2 & $\mathrm{~mm}$ \\
\hline Feed_x & 6 & $\mathrm{~mm}$ \\
\hline Feed_y & 12 & $\mathrm{~mm}$ \\
\hline Feed_thickness & 0.925 & $\mathrm{~mm}$ \\
\hline Feed_thickness & 39 & $\mathrm{~mm}$ \\
\hline R_out & 20 & $\mathrm{~mm}$ \\
\hline R_in & 11 & $\mathrm{~mm}$ \\
\hline P_x & 90 & $\mathrm{~mm}$ \\
\hline P_y & 10 & $\mathrm{~mm}$ \\
\hline Slot_x & 2 & $\mathrm{~mm}$ \\
\hline Sot_y & 2 & \\
\hline
\end{tabular}

The proposed antenna geometry and the parametric study of the proposed antenna is fig. 2 which shows that by increasing the length of radiating patch reverberation frequency is reduced at $2.3 \mathrm{GHz}$ 


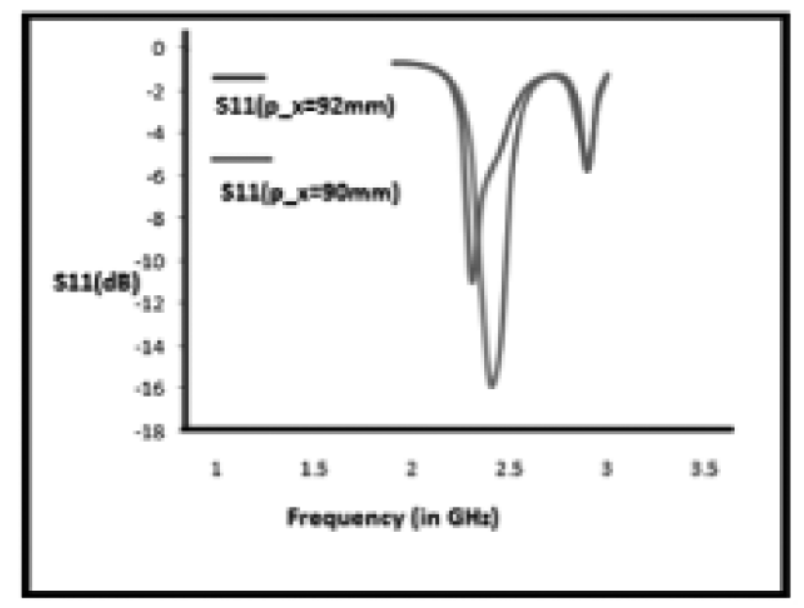

Figure 2. Parametric Analysis in return loss of proposed antenna for various value of p_x (length of patch)

Simulated return loss of the proposed antenna as seen in fig 3.The antenna resonates at frequency 2.4 GHz with a return loss of $-22.76 \mathrm{~dB}$ (at $\mathrm{p} \_\mathrm{x}=89.5 \mathrm{~mm}$ and $\mathrm{R} \_$in $\left.=11 \mathrm{~mm}\right)$.

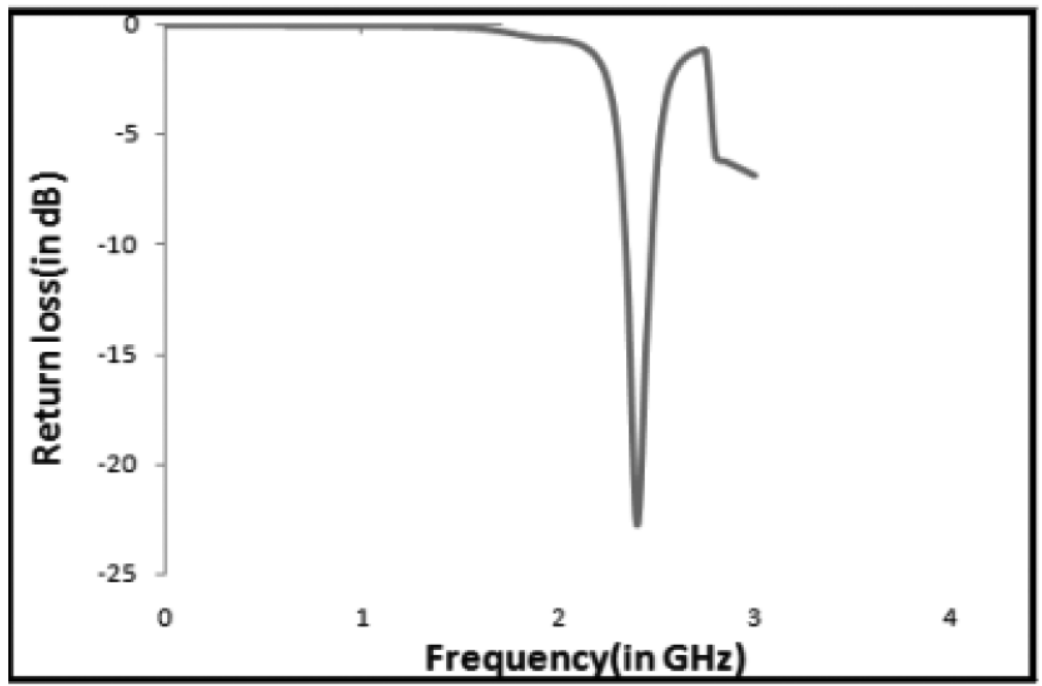

Figure 3. Proposed antenna return loss at frequency $2.4 \mathrm{GHz}$

The simulated results are well agreed for Bluetooth applications. The Bluetooth range is from $2.4 \mathrm{GHz}$ to $2.49 \mathrm{GHz}$, it means that $100 \mathrm{MHz}$ is the minimum bandwidth requirement for Bluetooth applications. The current distribution of the proposed antenna is shown in the Fig .4 


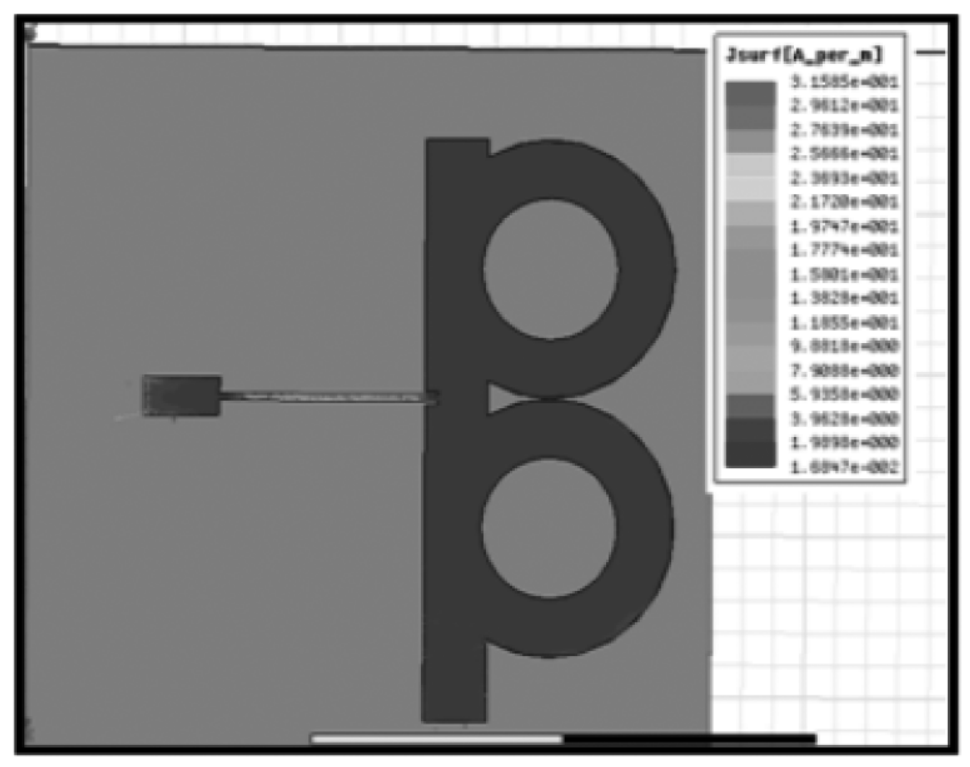

Figure 4. Proposed antenna current distribution

The antenna's current and voltage) distribution depends on the form of antenna. For eg, in a half wavelength dipole and a microstrip antenna, the current has the highest value at the middle while the current is zero at the side. By cutting a slot current distribution changed which cause change in s11. In microstrip antenna is a three-layer structure such as ground, substrate and a radiating patch. The ground plane at the bottom and the dielectric substrate above it and the radiating patch at the top. Patch is a low impedance because at the end of patch length it is an open circuit so current is zero $(\mathrm{V}=\mathrm{IR})$. The electric field is past an anti-node at each open circuit, and it alternates between strong positive and negative values. There is an electric field node and an anti-node magnetic field under the middle of the layer, and there is a line with negative electric field and strong magnetic field alternating. The patch radiation is typically viewed as radiation from two magnetic dipoles, one in the dielectric gap at either end of the surface, where the displacement current edE/dt provides the strength of the magnetic dipolar field. The magnetic dipoles run along the slot's length, and are in phase with each other. The patch sides do not radiate much, as compared to the holes at the ends. Some of the electric currents are just behind them on the bottom of the surface and on the ground floor, as they are on a microstrip. The field and ground currents are similar to each other and concealed in different directions.

The radiation pattern of antenna as shown in fig.5 for phi=0 deg at two different length patch such as $\mathrm{p} \_\mathrm{x}=$ $90 \mathrm{~mm}$ and $\mathrm{p} \_\mathrm{y}=92 \mathrm{~mm}$ 


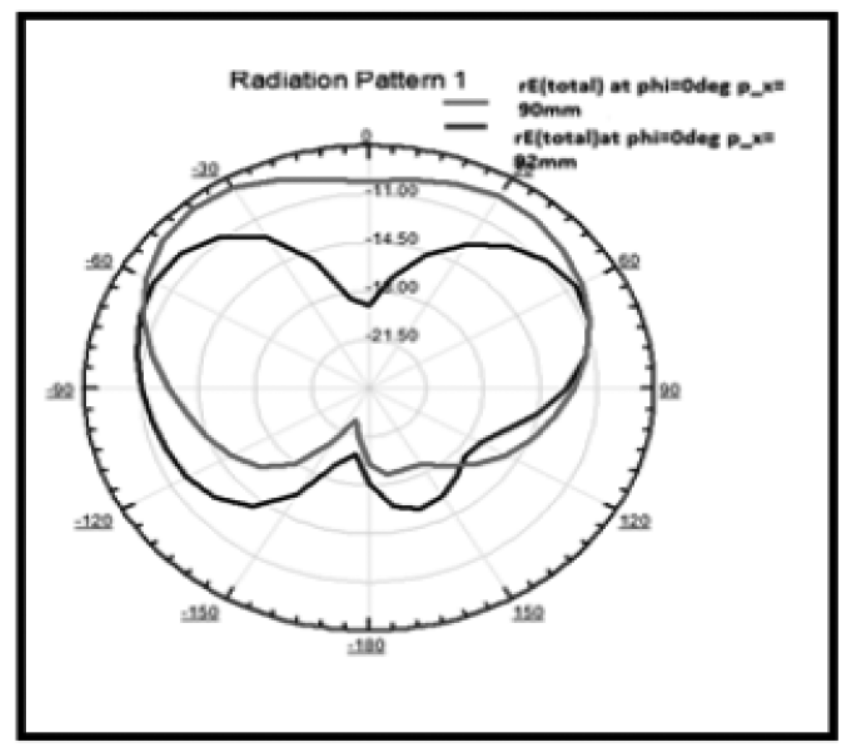

Figure 5. Proposed antenna radiation pattern

\section{CONCLUSION}

A $\beta$-shaped microstrip antenna has been designed to resonate at $2.4 \mathrm{GHz}$ for Bluetooth applications. A parametric analysis has been performed to recognize the resonant activities of the proposed antenna. 2D radiation pattern and $\mathrm{S} 11$-parameter values the $\beta$ shaped antenna is presented in the paper.

\section{REFERENCES}

C.A. Balanis. 1999. Antenna theory analysis and design, John Wiley \&sons, Inc,2 (1).

G. A. Deschamps " 1953, Microstrip microwave antennas 3rd USAF Symposium on Antennas.

J. Q. Howell. 1980. Microstrip antennas IEEE Antenna Propag Soc Int Symp.

K. F. Lee, K. M. Luk, K. F. Tong, S. M. Shum, T. Huyn and R. Q. Lee 1997. Experimental and Simulation Studies of the Coaxially Fed U-slot Rectangular Patch IEEE Proceedings of Microwave Antenna Propagation,

S. Sadat, M. Fardis, F. Geran, and G. Dadashzadeh, 2007. compact microstrip square-ring slot antenna for UWB applications, Progress In Electromagnetics Research.

H. R. Hassani and D. M Syahkal, 1995. Study of Electromagnetically Coupled Stacked Rectangular Patch Antenna, IEEE Proceedings of Microwave Antenna Propagation,

J. S. Kuo and K. L. Wong 2001. A Compact Microstrip Antenna with Meandering Slots in the Ground Plane," Microwave and Optical Technology Letters.

H. F. Pues and A. R. Van De Capelle 1989. Experimental and Simulation Studies of the Coaxially Fed U-slot Rectangular Patch IEEE Proceedings of Microwave Antenna Propagation,

K. W. Loi, S. Uysal and M. S. Leong, 1998 Design of Wideband Microstrip Bowtie Patch Antenna Proceedings of Institute Electrical Engineering Microwave Antenna Propagation,

A.B. Nandgaonkar and Shankar B. Deosarkar 2009 Broadband Stacked Patch Antenna for Bluetooth applications Journal of Microwaves, Optoelectronics and Electromagnetic Applications, 8-1. 